\title{
Understanding and Designing Sociotechnical Systems to Support the Impression Management Practices of Online Freelance Workers
}

Eureka Foong

Northwestern University

Evanston, IL 60202 USA

eureka@u.northwestern.edu
Permission to make digital or hard copies of all or part of this work for personal or classroom use is granted without fee provided that copies are not made or distributed for profft or commercial advantage and that copies bear this notice and the full citation on the first page. Copyrights for components of this work owned by others than ACM to post to post on servers or to redistribute to lists, requires prior

and, FL, USA.

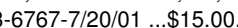

htp://dx.doi.org/10.1145/3323994.3371017

\begin{abstract}
A growing number of freelancers worldwide are involved in online, project-based knowledge work. Compared to employees in organizations, freelancers face serious challenges securing work and mitigate this by constructing favorable impressions on peers and clients. Sociotechnical systems present new opportunities and challenges to support impression management and two factors that influence it: 1) audience understanding and 2) gender role constraints. The goal of my dissertation is to understand and design sociotechnical systems that support freelancers' impression management. First, I will study and design online feedback exchange (OFE) systems that can help freelancers better understand their audiences by providing feedback on projects and portfolios. Second, I will investigate how gender role constraints influence freelancers' pricing behavior in online labor marketplaces. My research will contribute a novel OFE system for improving the quality of freelancers' portfolios and knowledge of gender differences in freelancers' pricing behavior to guide the design of sociotechnical systems that better support this emerging workforce.
\end{abstract}

\section{Author Keywords}

Freelancing; online work; online labor marketplaces; impression management; pay; feedback; crowdsourcing 


\section{Introduction and Background}

Online labor marketplaces, such as Upwork [2] and Freelancer.com [1], enable millions of freelancers to participate in a variety of online, project-based knowledge work worldwide [23]. For example, through an online labor marketplace, a freelance web designer in the United States (US) can design a website for a non-profit organization in Australia, while a freelance writer in the Philippines can help a small-business owner in the US proofread a business proposal. As more and more people participate in online freelance work, human-computer interaction $(\mathrm{HCl})$ scholars need to develop a better understanding of how systems might overcome challenges, such as creating motivating career ladders for freelancers and improving the design of freelance tasks [20,37].

Compared to employees in organizations, freelancers face acute challenges securing work, which they mitigate by constructing favorable impressions on clients (e.g., [31, 34, $8,36,32,5,15])$. Impression management is the process of constructing favorable impressions in others' minds of one's attributes through various behaviors [24]. For example, freelancers in the United Kingdom (UK) media industry use multiple job titles throughout their career to appeal to the needs of different organizations [30]. This pressure to create favorable impressions creates a form of "invisible" or undervalued labor that can make it challenging for people from all walks of life to gain employment as freelancers [3]. For example, many freelance journalists and writers spend hours every week refining an online persona for followers on Twitter and Facebook $[28,6]$.

To develop sociotechnical systems [38] that better support freelancers, it is imperative for $\mathrm{HCl}$ researchers to understand the situational factors that influence how freelancers manage their impressions on others. Two important situa- tional factors that influence impression construction include 1) one's understanding of a target audience's values and preferences, and 2) one's role constraints in society, such as gender [24]. A person's understanding of their audience can influence the content of their impressions [24]. People rely on feedback to improve their audience understanding and construct more effective impressions of themselves, for example in online dating [17]. Additionally, gender role constraints can bias women's impression management behaviors during the hiring process and in business negotiations, which can lead to inequities in pay (e.g., [4]).

Despite the importance and burden of impression management on the livelihood of freelancers, $\mathrm{HCl}$ scholars know relatively little about how sociotechnical systems might support freelancers in constructing impressions of themselves online. Instead, $\mathrm{HCl}$ research has focused almost exclusively on how freelancers use mobile technologies to support their work (e.g., [34, 33]) and how clients can more accurately infer freelancers' qualifications to prevent gaming (e.g., $[10,22,41])$.

In this dissertation, I will argue that $\mathrm{HCl}$ scholars can design systems that better support freelancers' impression management in two aspects: 1) helping freelancers' understand the impressions they stand to make through their work projects with crowdsourced feedback, and 2) studying the influence of gender role constraints on freelancers' online pricing behavior. Specifically, I will argue that when designing crowdsourced feedback systems to support freelancers, it is important to understand differences in individual sensemaking processes and design for feedback on portfolios, rather than just individual projects. I will also argue that female freelancers who participate in online labor marketplaces will set significantly lower pay rates for them- 
selves compared to men, which may be due to differences in impression management strategies.

\section{Research Questions}

My work will be motivated by two primary research questions:

- RQ 1: How we might design systems that enable freelancers to better understand and improve the impressions they make through their creative projects?

- RQ 2: What are ways that freelancers manage their impressions through their pricing behaviors in online labor marketplaces, and how might these behaviors be influenced by gender and impression management practices?

\section{Study 1: Designing Online Feedback Exchange (OFE) Systems to Support Understanding of Audience Impressions of Freelancers' Projects}

Study 1a: Understanding How Expertise Influences Sensemaking of Crowdsourced Feedback on Individual Projects

Freelancers in creative fields, such as graphic design, must constantly integrate feedback from clients to improve their work and increase their prospects for employment [29]. However, compared to employees in organizations, freelancers have limited opportunities to exchange feedback with peers unless they participate in formal collaborations or co-working spaces [35]. Online feedback exchange (OFE) systems can help freelancers supplement the feedback they receive from clients with timely, affordable, and authentic crowdsourced feedback from online communities, crowdworkers, and potential end users (e.g., [26, 40]). Yet, it is currently unclear how we might design OFE systems that can support freelancers in not only collecting highquality critique from online crowds, but also in interpreting and making sense of that critique, which research suggests may be influenced by domain expertise [21]

In this completed work [13], I describe differences in the sensemaking of crowdsourced feedback between novice and expert visual designers, through the lens of the dataframe theory of sensemaking. I conducted a study of 10 novice and 11 expert designers who used written feedback from Amazon Mechanical Turk (MTurk) workers to revise three hypothetical visual design projects. In line with dataframe theory [21], expert designers questioned inconsistent feedback more frequently than novice designers, enabling them to reflect on their design goals, consider new issues, and construct plans to collect more information (e.g., A/B tests). Moreover, while I predicted that domain experts would rely more heavily on their design knowledge to make sense of feedback, both experts and novices relied on their personal preferences to evaluate the feedback they received. This begins to explain why some novice designers in prior studies failed to examine deeper connections between crowdsourced feedback $[39,26]$. I contribute implications for designing OFE systems, such as providing freelance professionals with feedback on how projects are experienced by audiences, rather than judgments of quality.

Study 1b: CrowdFolio; The Impact of a Crowdsourced Feedback Tool to Improve the Quality of Freelancers' Portfolios of Work

Besides improving the impressions they stand to make through individual projects, freelancers must also learn to improve the impressions they make through their portfo- 
lios of completed work. Portfolios are an evolving, curated set of projects a professional has worked on [25]. Freelancers must regularly curate their highest quality projects to reflect their skill and style. However, they may struggle to do this because they may be poor judges of their own work and their understanding of their clients' and followers' preferences may be limited [11, 27]. Creative professionals could use OFE to obtain feedback on their portfolios, but current OFE systems provide specific evaluations of individual projects, rather than holistic evaluations of portfolios. In my remaining research, I will design an OFE system to provide crowdsourced feedback on freelancers' portfolios of completed work.

In collaboration with Adobe Research, I am building CrowdFolio, a system that crowdsources feedback on three dimensions of a portfolio: visual attractiveness of projects, design specialties conveyed, and styles shown in a portfolio. When aggregated, these dimensions represent an overall impression of a portfolio. These design choices were made based on my formative work, which included four hours of participant observations at a university-level portfolio design course, nine interviews with freelance designers recruited via Upwork [2], and three clients and hiring managers. I plan to evaluate the CrowdFolio system with at least 30 freelance graphic designers in the US with Behance portfolios in a between-subjects experiment, where participants will be asked to curate their portfolios before and after using CrowdFolio. Then, three clients or hiring managers will be asked to rate the quality of participants' curation choices. Through this work, I will contribute a nove system that can support freelancers in making decisions to improve the impressions their portfolios make.

\section{Study 2: Understanding the Influence of Gender Role Constraints on Impression Management through Freelancers' Online Pricing Behavior}

Study 2a: Describing Gender Differences in Freelancers' Pricing Behaviors in Online Labor Marketplaces

Besides audience understanding, role constraints, such as gender, also have a significant influence on the content of one's impressions (e.g., [16, 24]). Gender role constraints have a significant influence on impression management behavior, specifically during hiring and negotiation processes (e.g., [4]), that could lead to disparities in outcomes such as pay. For example, women are less likely to initiate negotiations for fear of appearing too aggressive (e.g., [4]). However, online labor marketplaces could reduce the influence of gender role constraints on pricing behavior by making freelancers' pay rates more transparent to one another, which is one approach to reducing pay disparities in offline labor markets [7]. While some research has found gender disparities in pay in online platforms with platformdetermined rates [9], we lack an understanding of how gender and impression management concerns influence pay rates that are determined by freelancers themselves.

In this completed study [14], I described the influence of freelancers' inferred gender on self-determined hourly bill rates on Upwork, one of the largest online labor marketplaces in the world [2]. Applying causal inference techniques [19] on a dataset of 55,518 public profiles of US workers on Upwork, I learned that female freelancers asked for lower median hourly bill rates overall than male freelancers in my dataset, both before and after taking into account potential covariates, such as job category, education 
level, and offline and online work experience. Nevertheless, women also worked a higher number of total hours on average than men, leading to similar levels of estimated revenue. Hence, it is currently unclear if female freelancers set lower rates for themselves online as a way to conform to gender role expectations (as impression management theory would predict), or to increase their prospects of employment in competitive online labor marketplaces.

Study 2b: Understanding Gender Differences in Freelancers' Online Pricing Behavior

In my remaining research, I seek to clarify whether gender differences in freelancers' pricing behavior arise from impression management concerns, or as a strategy for competing with other freelancers. I will constrain the scope of this study to the experiences of freelancers in creative media industries, such as graphic design, who increasingly engage in non-standard work arrangements such as freelancing (e.g. [18]). I propose a mixed-methods approach grounded in freelancers' accounts of their own experiences. First, I will conduct semi-structured interviews with at least 30 full-time freelancers in the US to understand their pricing strategies. I plan to ask participants questions to identify their pricing strategies, sources of information used, awareness of pay rates and discrepancies in pay, and the role of pricing in impression management. After generating themes from these interviews, I will conduct an electronic survey with a representative sample of freelancers who use online labor marketplaces and other websites to market their services to understand the prevalence of these pricing strategies by gender.

\section{Current and Expected Contributions}

At a high level, my work presents a theory for designing sociotechnical systems that can support freelancers in the invisible labor of managing their impressions on clients and peers. In Studies 1a and 1b, I will investigate the design of OFE systems [12] that can support freelancers in understanding the preferences and values of their audiences through feedback on individual projects and collections of completed work. In Studies $2 \mathrm{a}$ and $2 \mathrm{~b}$, I will characterize the influence of gender role constraints on the pricing behavior of freelancers in the US. More broadly, Studies $2 a$ and $2 \mathrm{~b}$ will expand HCl's understanding of the role of gender in users' experiences with sociotechnical systems, as well as extend theories of gender and impression management.

\section{Expected Benefits from Participation in Doctoral Consortium}

Through participation in this Doctoral Consortium at GROUP, I am primarily hoping to exchange valuable feedback with other students and faculty about the framing and value of my contributions to group work research. As I complete Studies $1 \mathrm{~b}$ and $2 \mathrm{~b}, \mathrm{I}$ am excited to have the opportunity to learn how I might better situate my research within the computer-supported cooperative work literature.

\section{REFERENCES}

[1] 2018. Freelancer - Hire \& Find Jobs. (2018). https://www.freelancer.com/

[2] 2019. Upwork - Hire Freelancers \& Get Freelance Jobs Online. (2019). https : / www . upwork . com/

[3] Adam Arvidsson, Alessandro Gandini, and Carolina Bandinelli. 2016. Self-Branding among Freelance Knowledge Workers. In Invisible Labor: Hidden Work in the Contemporary World. University of California Press. 
[4] Linda Babcock and Sara Laschever. 2009. Women Don't Ask: Negotiation and the Gender Divide. Princeton University Press. Google-Books-ID: k6vd7PJUFmYC.

[5] Helen Blair. 2003. Winning and losing in flexible labour markets: The formation and operation of networks of interdependence in the UK film industry. Sociology: The Journal of the British Sociological Association 37, 4 (Nov. 2003), 677-694. DOI :

http://dx.doi.org/10.1177/00380385030374003

[6] Cara Brems, Martina Temmerman, Todd Graham, and Marcel Broersma. 2017. Personal branding on Twitter: How employed and freelance journalists stage themselves on social media. Digital Journalism 5, 4 (2017), 443-459. DOI :

http://dx.doi.org/10.1080/21670811.2016.1176534

[7] Emilio J. Castilla. 2015. Accounting for the Gap: A Firm Study Manipulating Organizational Accountability and Transparency in Pay Decisions. Organization Science 26, 2 (Feb. 2015), 311-333. DOI : http://dx.doi.org/10.1287/orsc. 2014.0950

[8] Susan Christopherson. 2008. Beyond the Self-expressive Creative Worker An Industry Perspective on Entertainment Media. Theory Culture \& Society 25, 7-8 (Dec. 2008), 73-95. DOI : http://dx.doi.org/10.1177/0263276408097797

[9] Cook, Cody, Diamond, Rebecca, Hall, Jonathan, List, John A., and Paul Oyer. 2018. The Gender Earnings Gap in the Gig Economy: Evidence from over a Million Rideshare Drivers. Technical Report Working Paper No. 3637. https://www.gsb.stanford.edu/ faculty-research/working-papers/ gender-earnings-gap-gig-economy-evidence-over-million-rideshare
[10] Maria Daltayanni, Luca de Alfaro, and Panagiotis Papadimitriou. 2015. WorkerRank: Using Employer Implicit Judgements to Infer Worker Reputation. In Proceedings of the Eighth ACM International Conference on Web Search and Data Mining (WSDM '15). ACM, New York, NY, USA, 263-272. DOI : http://dx.doi.org/10.1145/2684822.2685286 event-place: Shanghai, China.

[11] Deanna P Dannels and Kelly Norris Martin. 2008. Critiquing critiques: A genre analysis of feedback across novice to expert design studios. Journal of Business and Technical Communication 22, 2 (April 2008), 135-159. DOI :

http://dx.doi.org/10.1177/1050651907311923

[12] Eureka Foong, Steven P Dow, Brian P Bailey, and Elizabeth M Gerber. 2017a. Online feedback exchange: A framework for understanding the socio-psychological factors. In Proceedings of the 27th Annual ACM Conference on Human Factors in Computing Systems. DOI :

http://dx.doi.org/10.1145/3025453.3025791

[13] Eureka Foong, Darren Gergle, and Elizabeth M. Gerber. 2017b. Novice and Expert Sensemaking of Crowdsourced Design Feedback. Proceedings of the ACM on Human-Computer Interaction 1, 45 (Dec. 2017). DOI : http://dx. doi .org/10.1145/3134680

[14] Eureka Foong, Nicholas Vincent, Brent Hecht, and Elizabeth M. Gerber. 2018. Women (Still) Ask For Less: Gender Differences in Hourly Rate in an Online Labor Marketplace. Proc. ACM Hum.-Comput. Interact. 2, CSCW (Nov. 2018), 53:1-53:21. DOI : http://dx.doi.org/10.1145/3274322 
[15] Alessandro Gandini. 2016. Digital work: Self-branding and social capital in the freelance knowledge economy. Marketing Theory 16, 1 (March 2016), 123-141. DOI :

http://dx.doi.org/10.1177/1470593115607942

[16] Erving Goffman. 1990. The Presentation of Self in Everyday Life. Penguin Books.

http: //books . google. com/books?id=032vnQEACAAJ\& $\mathrm{dq}=$ the+presentation+of+self+in+everyday+life+ gof $f$ man\&hl $=\& c d=2 \&$ source $=$ gbs_api

[17] Rebecca D. Heino, Nicole B. Ellison, and Jennifer L. Gibbs. 2010. Relationshopping: Investigating the market metaphor in online dating. Journal of Social and Personal Relationships 27, 4 (June 2010), 427-447. DOI :

http://dx.doi.org/10.1177/0265407510361614

[18] David Hesmondhalgh and Sarah Baker. 2013. Creative Labour : Media Work in Three Cultural Industries. Routledge. DOI :

http://dx.doi.org/10.4324/9780203855881

[19] Guido W. Imbens and Donald B. Rubin. 2015. Causal Inference in Statistics, Social, and Biomedical Sciences. Cambridge University Press. Google-Books-ID: Bf1tBwAAQBAJ.

[20] Aniket Kittur, Jeffrey V Nickerson, Michael Bernstein, Elizabeth M Gerber, Aaron Shaw, John Zimmerman, Matt Lease, and John Horton. 2013. The future of crowd work. In Proceedings of the 16th ACM Conference on Computer Supported Cooperative Work \& Social Computing. ACM, New York, New York, USA, 1301-1318. DOI :

http://dx.doi.org/10.1145/2441776.2441923
[21] Gary Klein, W Seick, D Peluso, and J Smith. 2007. FOCUS: A model of sensemaking. Technical Report. Klein Associates Inc.

http://scholar.google.com/scholar?q=related: SSFdK1TkSAOJ :

scholar. google. $\operatorname{com} / \& h l=e n \& n u m=20 \& a s_{-} s d t=0,5$

[22] Marios Kokkodis, Panagiotis Papadimitriou, and Panagiotis G. Ipeirotis. 2015. Hiring Behavior Models for Online Labor Markets. In Proceedings of the Eighth ACM International Conference on Web Search and Data Mining (WSDM '15). ACM, New York, NY, USA, 223-232. DOI :

http://dx.doi.org/10.1145/2684822.2685299

[23] Otto KÃd'ssi and Vili Lehdonvirta. 2016. Online Labour Index: Measuring the Online Gig Economy for Policy and Research. Technical Report 74943.

https ://mpra.ub. uni-muenchen.de/74943/

[24] Mark R Leary and Robin M Kowalski. 1990. Impression Management: A Literature Review and Two-Component Model. Psychological Bulletin 107, 1 (1990), 34-47.

[25] Harold Linton. 2012. Portfolio Design. W.W. Norton \& Company. Google-Books-ID: ZEQppwAACAAJ.

[26] Kurt Luther, Jari-Lee Tolentino, Wei Wu, Amy Pavel, Brian P Bailey, Maneesh Agrawala, Bjorn Hartmann, and Steven P Dow. 2015. Structuring, aggregating, and evaluating crowdsourced design critique. Proceedings of the 18th ACM Conference on Computer Supported Cooperative Work \& Social Computing (2015), 473-485. DOI :

http://dx.doi.org/10.1145/2675133.2675283 
[27] Jennifer Marlow and Laura Dabbish. 2014. From rookie to all-star: Professional development in a graphic design social networking site. Proceedings of the 17th ACM Conference on Computer Supported Cooperative Work \& Social Computing (Feb. 2014), 922-933. DOI :

http://dx.doi.org/10.1145/2531602.2531651

[28] Alice E. Marwick. 2013. Status Update: Celebrity, Publicity, and Branding in the Social Media Age. Yale University Press. Google-Books-ID: xcrYAQAAQBAJ.

[29] Jasper O'Leary, Holger WinnemÃüller, Wilmot Li, Mira Dontcheva, and Morgan Dixon. 2018. Charrette:

Supporting In-Person Discussions around Iterations in User Interface Design. ACM Press, 1-11. DOI: http://dx.doi.org/10.1145/3173574.3174109

[30] Kerry Platman. 2004. âĂ ̈̈Portfolio CareersâĂŹ and the Search for Flexibility in Later Life. Work, Employment and Society 18, 3 (Sept. 2004), 573-599. DOI : http://dx.doi.org/10.1177/0950017004045551

[31] Lorraine Rowlands and Jocelyn Handy. 2012. An addictive environment: New Zealand film production workersâĂŹ subjective experiences of project-based labour. Human Relations 65, 5 (May 2012), 657-680. DOI : http://dx.doi.org/10.1177/0018726711431494

[32] Caroline Ruiner and Ursula Liebhart. 2018. How multi-optional experts maintain and enhance their employability. German Journal of Human Resource Management: Zeitschrift fur Personalforschung 32, 1 (Feb. 2018), 52-74.

http://search.ebscohost. com/login.aspx?direct= true \&db=psyh\&AN=2018-07842-004\&site=ehost - live

[33] Kirsten Sadler, Toni Robertson, and Melanie Kan. 2009. Exploring the Project Transitions and Everyday
Mobile Practices of Freelancers: Emergent Concepts from Empirical Studies of Practice. In Proceedings of the 21st Annual Conference of the Australian Computer-Human Interaction Special Interest Group: Design: Open 24/7 (OZCHI '09). ACM, New York, NY, USA, 81-88. DOI :

http://dx.doi.org/10.1145/1738826.1738840

[34] Kirsten Sadler, Toni Robertson, Melanie Kan, and Penny Hagen. 2006. Balancing Work, Life and Other Concerns: A Study of Mobile Technology Use by Australian Freelancers. In Proceedings of the 4th Nordic Conference on Human-computer Interaction: Changing Roles (NordiCHI '06). ACM, New York, NY, USA, 413-416. DOI :

http://dx.doi.org/10.1145/1182475.1182525 event-place: Oslo, Norway.

[35] Clay Spinuzzi. 2012. Working Alone Together: Coworking as Emergent Collaborative Activity. Journal of Business and Technical Communication 26, 4 (Oct. 2012), 399-441. DOI : http://dx.doi.org/10.1177/1050651912444070

[36] Stefan Suess and Johannes Becker. 2013. Competences as the foundation of employability: a qualitative study of German freelancers. PERSONNEL REVIEW 42, 1-2 (2013), 223-240. DOI : http://dx.doi.org/10.1108/00483481311309393

[37] Ryo Suzuki, Niloufar Salehi, Michelle S Lam, Juan C Marroquin, and Michael S Bernstein. 2016. Atelier: Repurposing Expert Crowdsourcing Tasks as Micro-internships. In Proceedings of the 2016 Conference on Human Factors in Computing. 2645-2656. DOI :

http://dx.doi.org/10.1145/2858036.2858121 
[38] E L Trist and K W Bamforth. 1951. Some social and psychological consequences of the Longwall method of coal-getting: An examination of the psychological situation and defences of a work group in relation to the social structure and technological content of the work system. Human Relations 4, 1 (1951), 3-38. https://journals.sagepub.com/doi/pdf/10.1177/ 001872675100400101

[39] Anbang Xu, Shih-Wen Huang, and Brian P Bailey. 2014. Voyant: Generating structured feedback on visual designs using a crowd of non-experts. In Proceedings of the 17th ACM conference on Computer supported cooperative work \& social computing. 1433-1444.

http://dl .acm.org/citation. cfm?id=2531604
[40] Anbang Xu, Huaming Rao, Steven P Dow, and Brian P Bailey. 2015. A classroom study of using crowd feedback in the iterative design process. In the 18th ACM Conference. ACM Press, New York, New York, USA, 1637-1648. DOI :

http://dx.doi.org/10.1145/2675133.2675140

[41] Jiang Yang, Lada A. Adamic, and Mark S. Ackerman. 2008. Crowdsourcing and Knowledge Sharing: Strategic User Behavior on Taskcn. In Proceedings of the 9th ACM Conference on Electronic Commerce (EC '08). ACM, New York, NY, USA, 246-255. DOI :

http://dx.doi.org/10.1145/1386790.1386829 event-place: Chicago, II, USA. 